\title{
Development of Rotary Piston Engine Worldwide
}

\author{
Hu Chen, Cunyun Pan, Xiaojun Xu, \\ Xiang Zhang, Haijun Xu \\ College of Mechatronics Engineering and Automation, \\ National University of Defense Technology, \\ Changsha, China
}

\begin{abstract}
Energy and environmental problems are more serious at present and people realized that the development of traditional engines is limited, and all countries in the world began studying all kinds of new piston engines. In history, there have been various types of engine to replace the traditional ones. Of all these, the rotary piston engines are the most and most successful, including constant speed types, planetary types, and differential types. But they felled finally. With the development of science and technology, some problems seemingly hard to attack are resolved, new rotary engines, especially the differential type engine, are attracted more attentions gradually. Differential velocity engines are the focus of researchers for its characteristic of high power density, compact, smooth and capability of using various fuels. The technology of sealing, lubrication, and distribution used in traditional engines can also help to promote it.
\end{abstract}

Keywords-traditional piston engine; rotary piston engine; constant speed type; differential velocity engine

\section{INTRODUCTION}

Piston engine is the main power supply of all kinds of mobile equipments, and its power density directly affects the performance of mobile equipments. Compared with electric motor and gas turbine power, the piston engine has a smaller volume, simpler structure, and larger power density etc., therefore it becomes the most common source of power. However, after hundred years of improvement the traditional reciprocating piston engine is close to its limit and the possibility of improving its power density is small, so it cannot satisfy the demands of new mobile platform at present. For the above reasons, in the United States and Russia, representatives of science and technology, there is an upsurge to develop new engines. Relevant patent application number increased year by year. The research process of new type piston engine directly restricts the development of next-generation mobile equipment.

\section{RESEARCH STATUS OF ROTARY PISTON ENGINE}

Rotary piston engines have the basic characteristics different from traditional piston engine which is that under pressure torque, its piston rotates around the output shaft instead of reciprocating motion in the cylinder. The working process of the cylinders, although in some points it has its own characteristics, is almost simile as the original reciprocating work cycle in nature. On the one hand it is freed of the reciprocating inertia force for the privilege of high speed, and on the other hand, to a certain extent, it keeps the economy of traditional piston engine. So its emergence is the major technological changes on the structure of internal combustion engine [1].

Over the years, like this rotational structure, many kinds of solutions were put forward. By now in addition to Wankel rotary engine, others did not become a formal product. The main scheme that had ever been existed, according to its movement form, can be roughly divided into three types:

\section{A. Constant speed types}

Rotary pistons rotate at a certain angular velocity around a fixed center. Scraping blade is the main symbol of this piston. Generally speaking, radial seal of this piston is a problem, and when the scraping blade is under a big pressure there is a larger relative sliding and cantilever state outside of the piston. So its lubrication, cooling and strength are all difficult to design [2]. Figure 1 shows the two typical type of constant speed engine.

As shown in Figure 1(a), it was proposed by German scientists-[3] (In English it is called The rotatorque engine). There are a number of scraping blade piston arranged symmetrically on the rotor which divided the cylinder into sealed cavities of corresponding number. The volume of these sealed cavities varies according to the shape of cylinder, but its seal, lubrication and wear is difficult to deal with.

As shown in Figure 1(b), it is called Kwici engine and was applied for patent first by St. Lyell family in 1996 [4-6]. Using quadrilateral principle combined with cylinder shape, the volume of sealed cavity is changed.

\section{B. Planet types}

Rotary piston in the cylinder not only revolves around a fixed axis but also rotates around its self center, in this way volume change is achieved. Its cylinder shape includes inside and outside cycloid and its envelope, and its profile is shown in Figure 2(a), the representative of which is currently the formal product of Wankel rotary engine (as shown in Figure 2(b)). The gear ratio of Wankel rotary engine is 2:3, the cylinder line is double-arc cycloid, the 
piston line is three arc envelope for. In this rotary piston, there are less parts, more convenience for processing, no cantilever condition and good uniformly characteristic while heated, but due to the eccentric rotation, it is easy to produce cylinder seismic lines, which would disable the engine $[7,8]$.

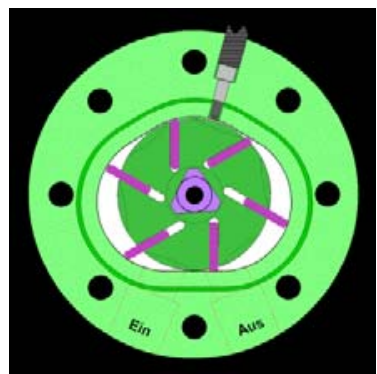

(a)

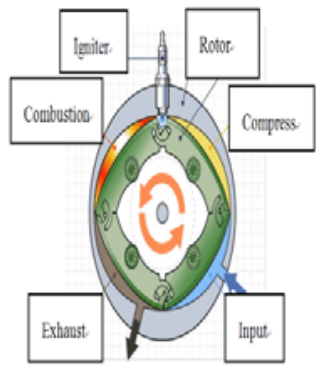

(b)
Figure 1. The typical engines of a constant speed. (a) New scraping rotor engine. (b) Kwisi engine.
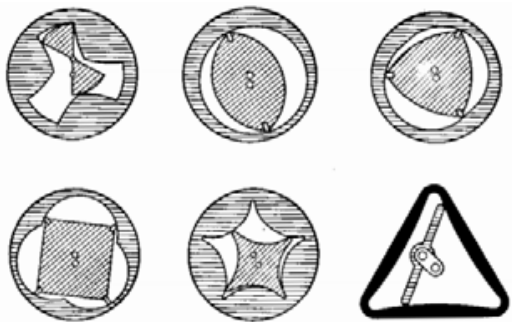

(a)

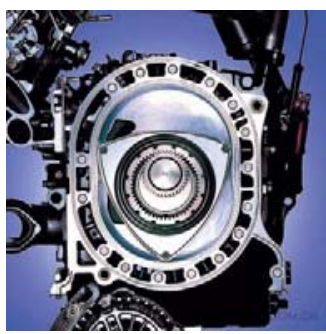

(b)

Figure 2. The structure of Planet type engine. (a) The profile of planetary motion. (b) Wankel rotary engine.

\section{Differential velocity types}

The rotary piston rotates around its output axis in various angular velocities. There are two rotors with different angular velocities in the kind of engine, the volumes between the pistons on the rotors change due to the two different angular velocities. Typical forms of differential type engine rotor worldwide are [9]:

- Circular cross section piston

As shown in Figure 3(a), it is called circular cylinder rotary engine [10]. Its characteristics are light weight, high efficiency, easy processing, and good sealing. It has two sets of rotor, a total of four pistons, which form four independent air chambers in the circular cylinder. Piston rings and seal rings are used for seal.

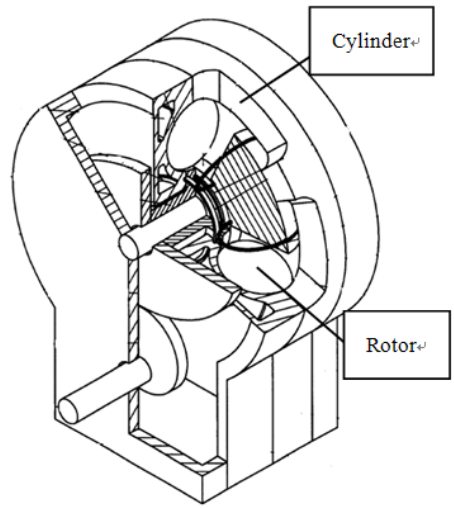

(a)

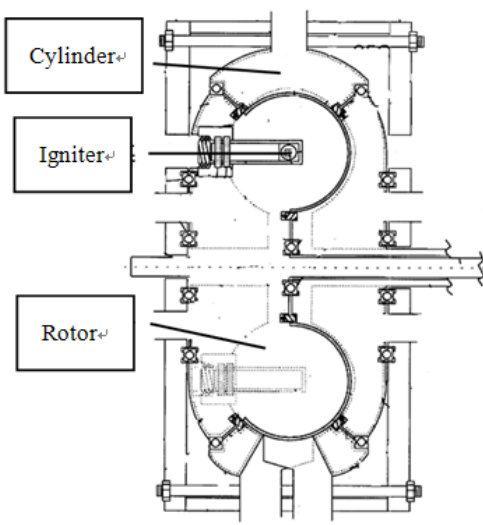

(b)

Figure 3. Structure of circular cylinder rotary engine. 

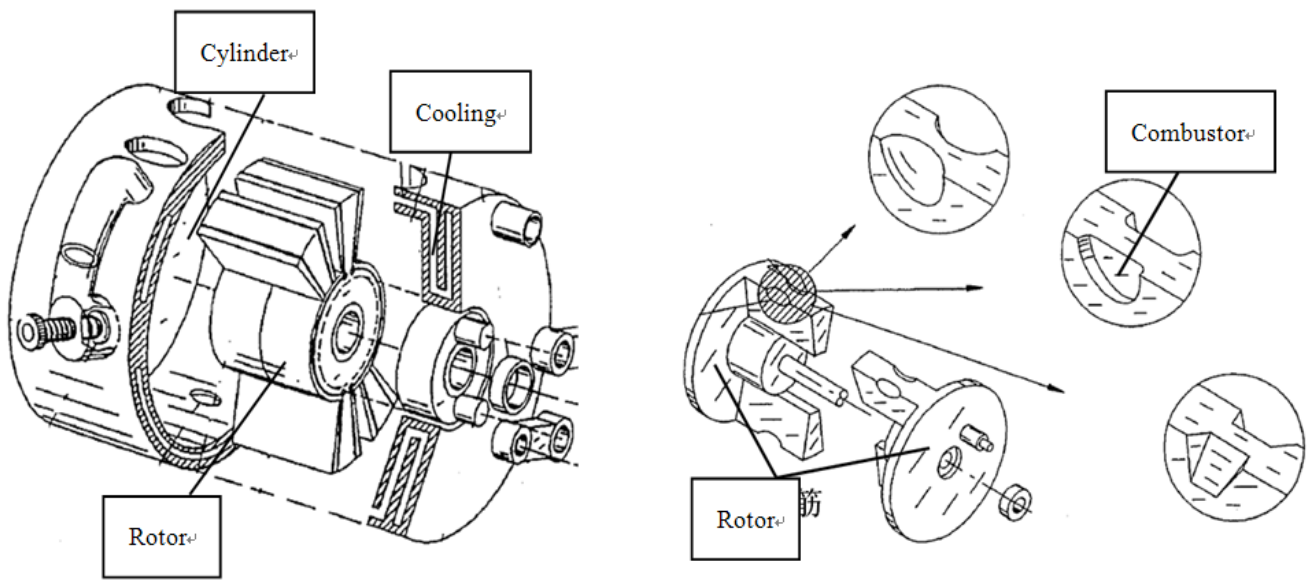

Figure 4. Is a kind of rotary piston engine with stiffener.

The pistons on the rotor are blade shapes, the cross section shapes of which are circular.

As shown in Figure 3(b), it is a rotary piston engine [11] from the United States. The structure of rotor is blade shape, and also the cross section shape is circular. Its characteristic is that the spark plugs are equipped on the piston of the rotor, and charged from the left end.

- Rectangular section piston

Shown in Figure 4, it is the rotary piston engine with stiffener [12]. The cross section shape of the piston is rectangular, and there are two sealing groove in radial and axial surface of the piston for sealing strips which are not continuous. The advantage of it is that every surface of the rotor is plane or cylinder which is easy to process and its volume between the two piston is larger than that of circular cross section engine in the same position. However, the impact of its cantilever cannot be neglected which would fell the sealing.
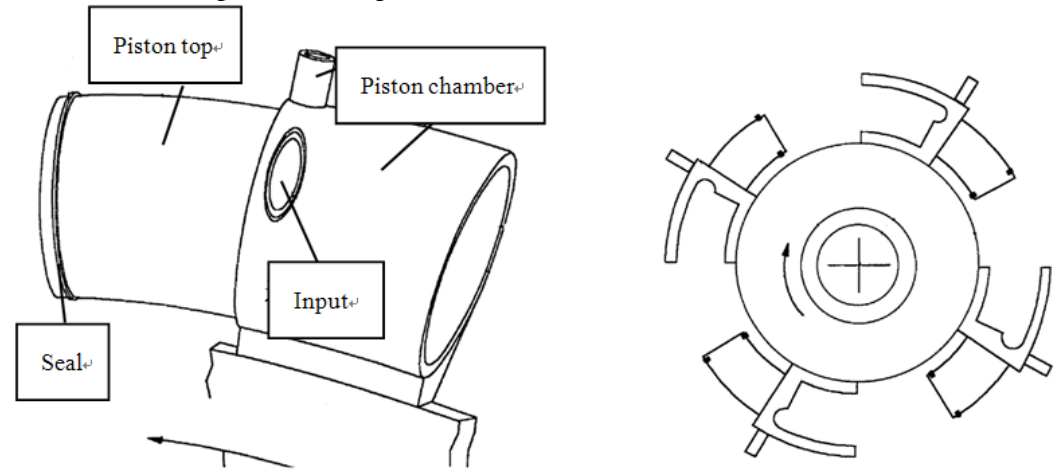

Figure 5. A kind of internal combustion engine.

- $\quad$ Piston with cylinder

Shown in Figure 5, it is a kind of internal combustion engine [13]. There are four pistons in every rotor and every piston is composed of piston top and piston chamber. The shape of piston top is curved cylindrical and it reciprocates in the next piston chamber. Piston rings on piston top are for sealing. There is only one hole on one side of piston chamber for input and exhaust in this internal combustion engine, which is close to the external cylinder body in the work time. There are corresponding input and exhaust pipes in the fixed position outside the cylinder body.

At present, people from most countries are researching differential type piston engine. For instance, Librovich from Britain presented a differential type piston engine with a non-circular gear transmission for constraining the two rotors. Meng Liangji from China applied an international patent called "interactive speed double rotor motor," with non-circular gears institution for constraining rotors rotation. Kurisu from Japan put grooves and rods into power transmission device in his engine. Morgado from the United States invented a differential type piston engine called "MYT Engine", and this engine had been made into a product and used for some experiment. Sakita from American applied for many differential type piston engine patents using elliptical gear and oval gear to restrict the motion of rotors. By 2012, there had been a prototype after many times test and in preparation for application. In 2012, Yo-Mobile Company in Russia promoted the first hybrid 
fuel used differential type engine, there are two blade pistons on each rotor in the engine, and it has a similar power transmission as MYT engine. According to the data, Yo-mobile Company plans to use the engine into unmanned aerial vehicles, trucks, boats and family power supply heating system in the near future. In addition, the German inventor Herbert invented a new type of generator (Kugelmotor) in 2002 which also adopted the mechanical structure of differential type piston engine.

\section{CONCLUSIONS}

Searching "F01C1" for the patents all over the world using SOOPAT, there were 39,482 patents applied for at home and abroad, and 6903 patents in the United States, 1648 patents in European, 9577 patents in Japan, 4956 patents in Germany, 700 patents Russia and 831 patents in China. Of all these, the number of rotary piston engines are the most, which includes constant speed types, planetary types and differential types, etc. With the development of science and technology, some problems seemingly hard to attack are resolved, new rotary engines, especially the differential type engine, are attracted more attentions gradually. Differential type piston engine flourished in recent years. It has the characteristic of high power density, compact, smooth and capability of using various fuels. The technology of sealing, lubrication and distribution used in traditional engines can also help to promote it. Up from the literature, the dynamic of differential type piston engine is limited, and there are still many unfound performance characteristics to excavate.

\section{REFERENCES}

[1] Fa Lu, Naibiao Yu, The Triangle Engine. National Defense Industry Press, Beijing, 1990.

[2] Foreign Wankel Rotary Engine. Shanghai science and technology information institution, Shanghai, pp. 1-4.

[3] www.rotatorque.com

[4] Zhiyuan Zuo, Jing Ding, et al., The Principle of quasi stirling engine. Journal of Small Internal Combustion Engine and Motorcycle, 5, pp. 56-59, 2006.

[5] Karl J. Scheibengraber, Internal Combustion Engines. United States Patent: 3175544, 1965-05-30.

[6] Jiles St Riller, A Kind of Quasi Turbine Engine. China patent: 03826218, 2006-04-12.

[7] Chinese Academy of Sciences-Institute of Mechanics. Rotary Piston Engine. Science Press, Beijing, pp. 21-38, 1973.

[8] Shiru Yu, Introduction of Wankel rotary engine. Journal of Physics teacher, p. 1, 1991.

[9] Deming Jiang, Principle of Internal Combustion Engine (the Second Edition). Chinese Agricultural Mechanical Press, Beijing, pp. 18-39, 1998.

[10] Weiyong Zheng, Circular Cylinder Rotary Engine. China patent: 03128413.2, 2003-04-23.

[11] Masami Sakita, Rotary Piston Engine. United States Patent, 6446595 b1, the 2002-09-10.

[12] David B. Wittry, High Power Rotary Engine with Variable Compression Ratio. United States Patent: 5622149, 1997-04-22.

[13] Masami Sakita, Rotary Piston Engine. United States Patent: 11485623 2008-06-17. 